\title{
KHẢO SÁT TỶ LÊ TRẺ TỪ 18-36 THÁNG Có BIỂU HIỆN RỐI LOAN PHỔ TƯ KỶ BẰNG THANG ĐIỂM M-CHAT TÁI TRƯờ'NG MẦM NON Ở THÀNH PHỐ CÀ MAU 2020
}

\author{
Nguyễn Minh Phương ${ }^{1}$, Trần Thiện Thắng ${ }^{1}$, Phan Việt Hưng ${ }^{1}$, Võ Văn Thi ${ }^{1}$ \\ Trịnh Thanh Thuý ${ }^{2}$ Ninh Thị Minh Hải ${ }^{2}$, Nguyễn Ngọc Thuỳ ${ }^{2}$
}

\section{TÓM TẮT}

Tổng quan: Rối loạn phổ tự kỷ là một rối loạn phức tap ở não bô đăc trưng bởi sư suy giảm trong giao tiểp và phản xa xã hội, hạn chế vê hành vi và cư xử lặp đi lặp lại. Viêc phát hiện sớm trẻ có nguy cơ rối loạn phổ tự kỷ để được tư vấn, theo dõi và can thiệp sớm là hết sức cần thiết. Mục tiêu: Khảo sát tỷ lệ và các yếu tố liên quan và dấu hiệu lâm sàng của trẻ từ 18-36 tháng có biểu hiện rối loạn phổ tự kỷ bằng thang điểm sàng loc trẻ tư kỷ (M-CHAT). Đối tượng và phương pháp nghiến cứu: nghiên cứu mô tả cắt ngang, giáo viên thực hiện đánh giá thang điểm M-CHAT cho 528 trẻ từ 18-36 tháng tuổi học tại trường mầm non ở thành phố Cà Mau. Kết quả: 302 $(57,2 \%)$ trẻ nam và $226(42,8 \%)$ nữ được ghi nhận, có $35(6,63 \%)$ trẻ dương tính với thang điểm M-CHÄT, các câu hỏi trong thang điểm M-CHAT có tỷ lệ dương tính cao là câu $3(85,71 \%), 11(80,0 \%), 19(88,57 \%)$. Tỷ lệ dương tính với thang M-CHAT cao ở nhóm trẻ chậm nói $(41,79 \%)$ và tré có phụ huynh $(78,95 \%)$, giáo viên $(61,82 \%)$ nghi ngờ về rối loạn phát triển, sư khác biệt có ý nghĩa thống kê. Kết luận: Tỷ trẻ có nguy cơ mắc rối loạn phổ tự kỷ là 6,63\% phản ánh độ nhay thang M-CHAT do giáo viên đánh giá chưa cao. Trẻ có chậm nói hay trẻ có phụ huynh hoặc giáo viên nghi ngờ có rối loạn phát triển là những nhóm có tỷ lệ dương tính cao.

Tư khóa: Rối loạn Phổ tự kỷ, thang điểm MCHAT, trẻ chậm nói

\section{SUMMARY}

\section{STUDY ON THE PERCENTAGE OF CHILDREN FROM 18 TO 36 MONTHS OLD WITH AUTISM SPECTRUM DISORDER WITH M-CHAT SCALE AT CAN THO CHILDREN'S HOSPITAL CLINIC}

Background: Autism spectrum disorder is a complex disorder characterized by impairment in communication and social reflection, limitations on behavior, and repetition of behaviors. Early detection of children at risk of autism spectrum disorder for consultation, monitoring, and early intervention is essential. Objective: This study aims at determining the prevalence, related factors and clinical signs of children aged 18-36 months with symptoms of autism

\section{${ }^{1}$ Trường Đại học Y dược Cần Tho}

²Bênh viên Sản Nhi Cà Mau

Chịu trách nhiệm chính: Nguyễn Minh Phương

Email: nmphuong@ctump.edu.vn

Ngày nhận bài: 2.3.2021

Ngày phản biên khoa hoc: 22.4.2021

Ngày duyệt bài: 29.4.2021 spectrum disorder using the Modified Checklist for Autism in Toddlers (M-CHAT). Materials and methods: A descriptive cross-sectional study was conducted in which teachers performed an M-CHAT questionnaire assessment for 528 children aged 18-36 months in kindergartens in Ca Mau city. Results: 302 $(57,2 \%)$ boys and $226(42,8 \%)$ females were recorded in which $35(6,63 \%)$ are positive on the M-CHAT questionnaire. Questions on the M-CHAT questionnaire with high positive rates are question $3(85,71 \%), 11$ $(80,0 \%), 19(88,57 \%)$. The rate of positive for the $M$ CHAT scale is high in groups of children with speech delay $(41,79 \%)$, children being suspicious of developmental disorders by parents $(78,95 \%)$, and children being suspicious of developmental disorders by teachers $(61,82 \%)$. The differences were statistically significant. Conclusions: The proportion of children at risk of autism spectrum disorder is 6,63\% reflecting the low sensitivity of the M-CHAT scale assessed by teachers. Children with speech delay or being suspicious of developmental disorders by parents or teachers are with higher positive rates.

Keywords: Autism spectrum disorder, M-CHAT questionnaire, speech delay.

\section{I. ĐĂT VẤN ĐỀ}

Rối loạn phổ tự kỷ là một rối loạn phát triển phức tạp của não bộ, thuật ngữ "phổ" chỉ sự đa dạng về triệu chứng cũng như mức độ của rối loạn, đặc trưng bởi những khó khăn trong giao tiếp và phản xạ xã hội, cũng như hạn chế về hành vi và cư xử lặp đi lặp lại [1],[2]. Theo CDC Hoa kỳ, tỷ lệ rối loạn phổ tự kỷ hiện nay là 1/68 trẻ [3] và tai Cần Thơ, qua nghiên cứu sàng loc có 2\% trẻ khám tại Bệnh Viện Nhi Đồng Cân Thơ có dấu hiệu nghi ngờ bệnh [6].

Việc chẩn đoán và can thiêp sớm bệnh cho trẻ mang lại những lợi ích rõ ràng, giúp trẻ phát triển theo hướng bình thường, tái hòa nhập cộng đồng, có thể tìm được việc làm, sống độc lập và thiết lâp được các mối quan hê. Vì vây các nhà chuyên môn đã thiết kế nhiều thang điểm dành nhằm phát hiện sớm trẻ tự kỷ và thang điểm $\mathrm{M}$ CHAT được xem như công cụ đâyy triển vọng, được sử dung phổ biến vì ít tốn kém, dễ thức hiện trong cô̂ng đồng, độ nhay, độ đắc hiệu lần lượt là 74,4\% và 99,9\% [4]. Mặc khác, phẩn lớn trẻ đến trường từ rất sớm và giáo viên tiếp xúc rất nhiều với trẻ nên trường mầm non là đia điểm phù hợp để tâm soát sớm rối loạn này. Vì 
những lí do trên, chúng tôi tiến hành: "Khảo sát tỷ lệ trẻ từ 18-36 tháng có biểu hiện rối loạn phổ tự kỷ bằng thang điêm M-CHAT tại trường mầm non ở Thành phố Cà Mau năm 2020" với mục tiêu: Khảo sát tỷ lệ, các yêu tố liên quan trẻ 1836 tháng có biểu hiện rối loạn phổ tự kỷ bằng thang điểm M-CHAT tại trường mầm non ơ Thành phố Cà Mau.

\section{II. ĐỐI TƯỢNG VÀ PHƯƠNG PHÁP NGHIÊN CỨU}

\section{1. Đối tượng nghiên cứu:}

Đối tượng nghiên cứu: 528 trẻ từ 18-36 tháng tuổi taii các trường mầm non ở Tp. Cà Mau.

Đia điểm nghiên cứu: 26 trường mầm non ở Thành phố Cà Mau.

Tiêu chuẩn chọn mẫu: tất cả trẻ từ 18-36 tháng tuổi tại 26 trường mầm non.

\section{Tiêu chuẩn loại trư:}

- Người nhà của trẻ từ chối tham gia khảo sát.

- Người nhà của trẻ không cung cấp đủ thông tin.

- Đối với những trẻ đến khám nhiều lần, chỉ lấy mẫu một lần duy nhất.

\section{Phương pháp nghiên cứu:}

\section{Thiêt kếnghiên cứu:}

- Nghiên cứu mô tả, cắt ngang có phân tích.

Cõ̃ mẫu nghiên cứu: 528 trẻ

Phương pháp chọn mẫu: Chọn mẫu thuận tiện

- Lập danh sách 26 trường mầm non, nhóm trẻ tại Thành phố Cà Mau

- Lâp danh sách trẻ từ 18-36 tháng học tại 26 trường mầm non/nhóm trẻ, có tổng 528 trẻ được thăm khám, đánh giá

Nội dung nghiên cứu:

- Tỷ lệ rối loạn phổ tự kỷ của trẻ theo thang điểm M-CHAT.

- Mối liên quan giữa mức độ rối loạn phổ tự kỷ của trẻ với giới tính, nhóm tuổi, tuổi thai và cân nặng lúc sinh.

- Dấu hiệu lâm sàng gồm: Phụ huynh nghi ngờ trẻ có rối loạn, giáo viên nghi ngờ trẻ có rối loạn, trẻ chậm nói so với tuổi và tiền sử chẩn đoán RLPTK.

\section{Phương pháp đánh giá:}

- Xác định câu trả lời:

\begin{tabular}{|c|c|}
\hline " Có"= Bình thường & Câu: 1, 3, 4, 6, 7, \\
$8,9,10,11,13,14$, \\
"Không" = Bất thường & $15,16,17,18,19,20$ \\
\hline "Có"= Bất thường & Câu: $2,5,12$ \\
\hline "Không"=Bình thường & \\
\hline
\end{tabular}

- M-CHAT-20 (+) = Nghi ngờ tự kỷ: khi có ít nhất 3 câu bất kỳ bất thường.

- M-CHAT-20 (-) = Không nghi ngờ tự kỷ: khi có dưới 3 câu bất kỳ bất thường.

Công cụ nghiên cứu:
- Giáo viên đánh giá thang điểm M-CHAT cho trẻ tại lớp học và sử dụng bộ công cụ thu thập thông tin soạn sẵn soạn trước để thu thập thông tin từ phụ huynh

- Giáo viên được tập huấn trước khi thu thập số liệu theo thang điểm M-CHAT

Phương pháp xử lý và phân tích số liệu:

- Dữ liệu được nhập và xử lý bằng phần mềm SPSS 20.0.

- Kiểm định X2 để kiểm định mối liên quan giữa các yếu tố.

- Tính tỷ suất chênh OR với khoảng tin cậy $95 \%$. Kiểm định có ý nghĩa thống kê khi $a<0,05$.

\section{KẾT QUẢ NGHIÊN CỨU}

\section{1. Đặc điểm đối tượng nghiên cứu}

Bảng 1: Đặc điểm của đôî tượng nghiên cứu

\begin{tabular}{|c|c|c|c|}
\hline \multicolumn{2}{|c|}{ Biến số } & Số & Tỷ lệ \\
\hline \multirow{2}{*}{ Nhóm tuổi } & 18-24 tháng & 160 & 30,30 \\
\hline & 25-36 tháng & 368 & 69,70 \\
\hline \multirow{2}{*}{ Giới } & Nam & 302 & 57,20 \\
\hline & Nũ̃ & 226 & 42,80 \\
\hline \multirow{2}{*}{ Nơi ở } & Trung tâm & 358 & 67,80 \\
\hline & Ngoại ô & 170 & 32,20 \\
\hline \multirow{2}{*}{$\begin{array}{l}\text { Người } \\
\text { chăm sóc } \\
\text { chính }\end{array}$} & Cha me & 360 & 68,18 \\
\hline & $\begin{array}{l}\text { Người thân } \\
\text { khác }\end{array}$ & 168 & 31,82 \\
\hline \multirow{2}{*}{$\begin{array}{l}\text { Mang thai } \\
\text { đủ tháng }\end{array}$} & Có & 480 & 90,91 \\
\hline & Không & 48 & 9,09 \\
\hline \multirow{2}{*}{$\begin{array}{c}\text { Cân nặng lúc } \\
\text { sinh }\end{array}$} & $\geq 2500$ gram & 495 & 93,75 \\
\hline & $<2500$ gram & 33 & 6,25 \\
\hline \multirow{2}{*}{$\begin{array}{c}\text { Gia đình } \\
\text { nghi ngờ trẻ } \\
\text { có rối loạn }\end{array}$} & Có & 38 & 7,20 \\
\hline & Không & 490 & 92,80 \\
\hline \multirow{2}{*}{$\begin{array}{l}\text { Giáo viên } \\
\text { nghi ngờ trẻ } \\
\text { có rối loạn }\end{array}$} & Có & 55 & 10,42 \\
\hline & Không & 473 & 89,58 \\
\hline \multirow{2}{*}{$\begin{array}{l}\text { Trẻ chấm nói } \\
\text { so với tuổi }\end{array}$} & Có & 67 & 12,69 \\
\hline & Không & 461 & 87,31 \\
\hline \multirow{2}{*}{$\begin{array}{c}\text { Tiền sử } \\
\text { chẩn đoán } \\
\text { RLPTK }\end{array}$} & Có & 3 & 0,57 \\
\hline & Không & 525 & 99,43 \\
\hline
\end{tabular}

Trẻ nam chiếm đa số với $57,20 \%$, lần lượt $7,20 \%, 10,42 \%$ trẻ có gia đình và giáo viên nghi ngời mắc rối loạn, $12,69 \%$ trẻ chậm nói và 0,57\% từng được chẩn đoán tự kỷ.

2. Tỷ lệ dương tính với thang điểm $M$ -

\section{CHAT:}

Bảng 2: Tỷ lệ trẻ dương tính với thang điểm M-CHAT

\begin{tabular}{|c|c|c|}
\hline Trẻ & Số lượng & Tỷ lệ (\%) \\
\hline M-CHAT (+) & 35 & 6,63 \\
\hline M-CHAT (-) & 392 & 93,37 \\
\hline
\end{tabular}


Trẻ dương tính với thang điểm M-CHAT chiếm 6,63\%.

Bảng 3: Kêt quả các câu hỏi trong thang điểm M-CHAT

\begin{tabular}{|c|c|c|c|c|c|}
\hline \multirow[t]{2}{*}{$\pi$} & \multirow[t]{2}{*}{ Câu hỏi nghiên cứu trong thang điểm M-CHAT } & \multicolumn{2}{|c|}{$\begin{array}{c}\text { Dương } \\
\text { tính }\end{array}$} & \multicolumn{2}{|c|}{ Âm tính } \\
\hline & & $\mathbf{n}$ & $\%$ & $\mathbf{n}$ & $\%$ \\
\hline 1 & Bé có nhìn theo khi bạn chỉ một điểm trong phòng không? & 10 & 28,57 & 25 & 71,43 \\
\hline 2 & Bạn có bao giờ tự hỏi liệu con bạn có bị điếc không? & 6 & 17,14 & 29 & 82,86 \\
\hline 3 & Con bạn có chơi trò đóng vai hay giả vờ không? & 30 & 85,71 & 5 & 14,29 \\
\hline 4 & Con bạn thích leo trèo lên đồ vật không? & 10 & 28,57 & 25 & 71,43 \\
\hline 5 & Chuyển động ngón tay bất thường đênn gần mắt không? & 5 & 14,29 & 30 & 85,71 \\
\hline 6 & Dùng ngón tay trỏ để yêu cầu hay giúp đỡ không? & 6 & 17,14 & 29 & 82,86 \\
\hline 7 & Có dùng ngón tay đế chỉ ban thứ bé thích thú không? & 9 & 25,71 & 26 & 74,29 \\
\hline 8 & Con bạn có thích chơi với những đứa trẻ khác không? & 10 & 28,57 & 25 & 71,43 \\
\hline 9 & Có khoe đồ chơi mới cho bạn không? & 22 & 62,86 & 13 & 37,14 \\
\hline 10 & Con ban có đáp lai khi được goi tên không? & 17 & 48,57 & 18 & 51,43 \\
\hline 11 & cười lại với bạn không? & 28 & 80,00 & 7 & 20,00 \\
\hline 12 & êng ồn xung quanh & 24 & 68,57 & 11 & 31,43 \\
\hline 13 & Con ban của ban có đi bô không? & 1 & $2 ., 6$ & 34 & 97,14 \\
\hline 14 & Có nhìn vào mắt bạn khi bạn nói chuyện với bé không? & 12 & 34,29 & 23 & 65,71 \\
\hline 15 & Con ban có bắt chước những điều ban làm không? & 13 & 37,14 & 22 & 62,86 \\
\hline 16 & Quay đầu theo nhìn khi bạn nhìn gì đó? & 20 & 57,14 & 15 & 42,86 \\
\hline 17 & Con bạn cố & 18 & 51,43 & 17 & 48,57 \\
\hline 18 & gì khi ban yêu câu làm không? & 15 & 42,86 & 20 & 57,14 \\
\hline 19 & Có nhìn & 21 & 88,57 & 14 & 11,43 \\
\hline 20 & Thích những hoạt động mang tính chất chuyến động? & 15 & 42,86 & 20 & 57,14 \\
\hline
\end{tabular}

Các câu có tỷ lệ dương tính nhiều nhất là câu 3,11 và 19 với tỷ lệ lần lượt là $85,71 \%, 80,00 \%$ và $88,57 \%$.

3. Các yếu tố liên quan và dấu hiệu lâm sàng ở trẻ 18-36 tháng có biểu hiện RLPTK với thang điểm M-CHAT:

Bảng 4: Một số yêu tố liên quan ở trẻ 18-36 tháng có biểu hiện RLPTK

\begin{tabular}{|c|c|c|c|c|c|c|}
\hline \multirow{2}{*}{\multicolumn{2}{|c|}{ Biến số }} & \multicolumn{2}{|c|}{ M-CHAT (+) } & \multicolumn{2}{|c|}{ M-CHAT (-) } & \multirow{2}{*}{$\mathbf{p}$} \\
\hline & & $\mathbf{n}$ & $\%$ & $\mathbf{n}$ & $\%$ & \\
\hline \multirow{2}{*}{ Nhóm tuổi } & $18-24$ tháng & 12 & 7,50 & 148 & 92,50 & \multirow{2}{*}{0,142} \\
\hline & $25-36$ tháng & 23 & 6,25 & 345 & 93,75 & \\
\hline \multirow{2}{*}{ Giới } & Nam & 25 & 8,28 & 277 & 91,72 & \multirow[b]{2}{*}{0,528} \\
\hline & Nũ̃ & 10 & 4,42 & 216 & 95,58 & \\
\hline \multirow{2}{*}{ Nơi ở } & Nông thôn & 28 & 7,82 & 330 & 92,18 & \multirow{2}{*}{0,423} \\
\hline & Thành thi & 7 & 4,12 & 163 & 95,88 & \\
\hline \multirow{2}{*}{$\begin{array}{c}\text { Người } \\
\text { chăm sóc }\end{array}$} & Cha me & 30 & 8,33 & 330 & 91,67 & \multirow{2}{*}{0,752} \\
\hline & Người thân khác & 5 & 2,98 & 163 & 97,02 & \\
\hline \multirow{2}{*}{$\begin{array}{l}\text { Mang thai } \\
\text { đủ tháng }\end{array}$} & Có & 34 & 7,08 & 446 & 92,92 & \multirow[b]{2}{*}{0,431} \\
\hline & Không & 1 & 2,08 & 47 & 97,92 & \\
\hline \multirow{2}{*}{$\begin{array}{l}\text { Cân nặng } \\
\text { lúc sinh }\end{array}$} & $<2500$ gram & 33 & 6,67 & 462 & 93,33 & \multirow{2}{*}{0,532} \\
\hline & $\geq 2500$ gram & 2 & 6,06 & 31 & 93,94 & \\
\hline
\end{tabular}

Không có yếu tố liên quan nào cho thấy làm tăng nguy cơ mắc rối loan phổ tự kỷ có ý nghĩa thống kê CHAT

Bảng 5: Dấu hiệu liên quan ở trẻ 18-36 tháng có biểu hiện RLPTK theo thang điêm M-

\begin{tabular}{|c|c|c|c|c|c|c|}
\hline \multirow{2}{*}{$\begin{array}{c}\text { Gia đình nghi ngờ trẻ } \\
\text { có rối loạn }\end{array}$} & Có & 30 & 78,95 & 8 & 21,05 & \multirow{2}{*}{$<0,001$} \\
\cline { 2 - 7 } & Không & 5 & 1,02 & 485 & 98,98 & \\
\hline $\begin{array}{c}\text { Giáo viên nghi ngờ } \\
\text { trẻ có rối loạn }\end{array}$ & Có & 34 & 61,82 & 21 & 38,18 & \multirow{2}{*}{$<0,001$} \\
\cline { 2 - 7 } & Không & 1 & 0,21 & 472 & 99,79 & \multirow{2}{*}{ Trẻ chậm nói } \\
\cline { 2 - 6 } & Có & 28 & 41,79 & 39 & 58,21 & \multirow{2}{*}{0,005} \\
\hline
\end{tabular}


TAP CHÍ Y HOC VIÊT NAM TÂP 502 - THÁNG 5 - SỐ 1 - 2021

\begin{tabular}{|c|c|c|c|c|c|c|}
\hline Tiền sử chẩn đoán & Có & 3 & 100,00 & 0 & 0,00 & \multirow{2}{*}{$<0,001$} \\
\cline { 2 - 6 } RLPTK & Không & 32 & 6,10 & 493 & 93,90 & $<$ \\
\hline
\end{tabular}

Trẻ có gia đình và giáo viên nghi ngờ mắc rối loạn có tỷ lệ dương tính cao và $100 \%$ trẻ có tiền sử chẩn đoán rối loạn phổ tự kỷ dương tính với thang điểm M-Chat

\section{BÀN LUẬN}

1. Đặc điểm đối tượng nghiên cứu. Trong nghiên cứu, chúng tôi ghi nhận tỷ lệ trẻ nam là $57,2 \%$, trẻ ở trung tâm thành phố chiếm $67,8 \%$, nhóm 25-36 tháng tuổi chiếm đến 69,7\% điều này có thể giải thích do mẫu ghi nhận tại thành phố Cà Mau nên phần lớn dân cư thuộc trung tâm và lứa tuổi trẻ $>24$ tháng cũng chiểm đa số hơn ở các trường mầm non. Trẻ được chăm sóc chín từ cha me chiếm $68,18 \%$, sinh đủ tháng là $90,91 \%$ và đủ cân là $93,75 \%$ điêuu này phù hợp với tình hình chăm sóc sức khoẻ bà mẹ trẻ em chung của tỉnh hiện nay.

Có đến 7,2\% phụ huynh nghi ngờ trẻ của mình có vấn đề về phát triển, trong khi số này ở giáo viên là $10,42 \%$, tỷ lệ này là phù hợp vì xét chung các rối loạn về phát triển bao gồm rối loạn phổ tự kỷ, chậm phát triển, rối loạn ngôn ngữ, rối loạn vận động... tỷ lệ thường khá cao, mặc khác sự phát triển của trẻ không đồng đều nên việc phụ huynh và giáo viên có thể nghi ngờ sự phát triển của con em mình là hoàn toàn phù hợp.

Chúng tôi cũng ghi nhận có 67 trẻ tương đương 12,69\% có chậm nói, nghiên cứu dùng mốc phát triển về ngôn ngữ để ghi nhận trẻ chậm nói, trẻ 18-24 tháng chưa nói được từ đơn và trẻ trên 24 tháng chưa nói được từ đôi được xác định là chậm nói. Nghiên cứu cũng ghi nhận 3 trẻ tương ứng $0,57 \%$ từng được chẩn đoán rối loạn phổ tự kỷ, tỷ lệ này cũng phù hợp với nghiên cứu ở Việt Nam của Nguyễn Thị Hương Giang và cộng sự [4]].

2. Tỷ lệ dướng tính với thang điểm $M$ CHAT. Kết quả khảo sát cho thấy tỷ lệ trẻ nguy cơ mắc rối loạn phổ tự kỷ qua sàng lọc bằng thang điểm M-CHAT là 6,63\%, tương đương với nghiên cứu của Nguyến Đức Trí (2014) trên 1369 trẻ tại quận Ninh Kiều thành phố Cần Thơ $(6,9 \%)[7]$, và cao hơn so với nghiên cứu của Trân Thiện Thắng (2019) trên 400 trẻ đến khám tại Bênh Viện Nhi Đồng Cần Thơ [6]. Sự khác biệt này do thiết kế nghiên cứu, chúng tôi thu thập dữ liệu M-CHAT từ giáo viên, họ ít được đào tạo về rối loạn cũng như thư tập thang điểm hơn các sinh viên y khoa trong nghiên cứu của tác giả Trần Thiện Thắng, nên tỷ lệ dương tính giả cao hơn là hoàn toàn phù hợp. Tuy nhiên với độ nhạy là $74,4 \%$ [4] và tỷ lệ rối loạn này trong cộng đồng khoảng 1,69\% [2] cho thấy tỷ lệ này rất cao, điều này phản ánh việc đánh giá của giáo viên là chưa được chính xác.

Nhóm câu hỏi dương tính cao nhất là câu $3,11,19$ với tỷ lệ lần lượt là $85,71 \%, 80,00 \%$, $88,57 \%$, các câu hỏi dương tính tỷ lệ thấp dưới $10 \%$ là các câu $2,5,6,7,13$.Câu hỏi số $3,11,19$ đều là các câu hỏi liên quan đến sự giới han về giao tiếp xã hội. Tất cả trẻ rối loạn phổ tự kỷ đều thể hiện những thiếu sót trong các mối quan hệ xã hội, chia sẽ cảm xúc và khả năng tưởng tượng, kết bạn [1],[5]. Mặc dù có tỷ lệ dương tính cao nhưng do trong nghiên cứu không có bác sĩ khám nên chưa thể xác định câu có tỷ lệ câu hỏi nào có tỷ lệ dương tính cao thì đồng thuận với tỷ lệ mắc rối loạn. So với nghiên cứu của tác giả Trần Thiện Thẳng (2019) câu hỏi số 6 lại là câu hỏi có tỷ lệ dương tính cao [6], kết quả này có thể chỉ ra sự đào tạo giáo viên thực hiện thang điểm M-CHAT chưa phù hợp vì vậy tỷ lệ trẻ dương tính rất cao như đã phân tích ở trên và các câu hỏi có tỷ lệ khác biệt nhiêu so với nghiên cứu khác.

3. Các yếu tố liên quan và biểu hiện lâm sàng. Trẻ nam nguy cơ mắc rối loạn nhiều hơn trẻ nữ với tỷ lệ nam:nữ là 1,87:1 là phù hợp vì tỷ lệ trẻ tự kỷ nam cao hơn nữ [6],[7]. Trẻ dương tính với M-CHAT có tỷ lệ khác nhau ở các nhóm nơi sống, nhóm tuổi, người chăm sóc, nhẹ cân lúc sinh và sinh non, tuy nhiên sự khác biệt không có ý nghĩa thống kê. Nhẹ cân và sinh non được ghi nhận là yếu tố có liên quan làm tăng tỷ lệ rối loạn phổ tự kỷ nhưng do trong nghiên cứu này mấu ghi nhận còn hạn chế nên chưa thể thấy được sự khác biêtt.

Có sự khác biệt rõ rệt về tỷ lệ trẻ có dẫu hiệu rối loạn phổ tự kỷ ở nhóm bị phụ huynh và giáo viên nghi ngờ về phát triển. Điều này hoàn toàn phù hợp vì những dấu hiệu dương tính trong thang điểm M-CHAT là những dấu hiệu về phát triển cảm xúc, xã hội của trẻ mà phụ huynh và giáo viên có thể dễ dàng nhận thây mà không cần qua đào tạo. Điêuu này cũng chứng tỏ các dấu hiệu nghi ngời của phụ huynh hay giáo viên là rất giá trị, nên khuyến cáo những trẻ bị nghi ngờ về phát triển sớm được tầm soát rối loạn phổ tự kỷ. Tỷ lệ dương tính ở nhóm trẻ chậm nói lên tới $41,79 \%$ so với $1,52 \%$ ở nhóm không chậm nói, sự khác biệt có ý nghĩa thống kê. Điều này hoàn toàn phù hợp vì biểu hiện chậm nói là dấu hiệu thường thấy ở trẻ rối loạn phổ tự kỷ và 
trong nghiên cứu này mốc phát triển để xác định trẻ chậm nói cũng là dấu hiệu báo động đỏ nguy cơ trẻ rối loạn phổ tự kỷ được khuyến cáo. 3 trẻ có tiền sử được chẩn đoán rối loạn phổ tự kỷ đều có M-CHAT dương tính, kết quả này cũng phản ánh độ đặc hiệu của thang M-CHAT là rất cao, các nghiên cứu khác ghi nhận giá trị này lên đến $99,9 \%$ [4].

\section{KẾT LUÂN}

- Qua sàng lọc 528 trẻ 18-36 tháng tuổi tại 26 trường mầm non bằng thang điểm M-CHAT do giáo viên thực hiện ghi nhận 6,63\% trẻ dương tính, tỷ lệ này phản ánh thang điểm $M$ CHAT do giáo viên mầm non thực hiện có độ nhạy thấp hơn những nghiên cứu khác.

- Trẻ có biểu hiện chậm nói so với tuổi hay bi gia đình và giáo viền nghi ngờ có vấn đề về phát triển có tỷ lệ dương tính cao lần lượt là $41,79 \%$, $78,95 \%$ và $61,82 \%$ và sự khác biệt có ý nghĩa thống kê. Các câu hỏi 3,11,19 trong thang điểm M-CHAT có tỷ lệ dương tính cao nhất lần lượt là $85,71 \%, 80,00 \%, 88,57 \%$.

\section{KIẾN NGH!:}

- Áp dụng sàng lọc trẻ RLPTK bằng thang điểm M-CHAT tại các trường mâm non đặc biệt nhóm trẻ chậm nói so với tuổi hoặc có phụ huynh, giáo viên nghi ngờ về phát triển.

- Tăng cường tập huấn cho giáo viên thực hiện thang điểm M-CHAT, đánh giá độ nhạy độ đặc hiệu của thang điểm khi được áp dụng tại các trường mầm non ở tỉnh Cà Mau

\section{TÀI LIÊU THAM KHẢO}

1. American Psychiatric Association (2013) Diagnostic and Statistical Manual of Mental Disorders $5^{\text {th }}$ Edition, Washington DC, p.50

2. CDC (2020). Basics about Autism Spectrum Disorder (ASD) | NCBDDD | CDC [Internet]. Centers for Disease Control and Prevention. 2020 [cited 2020 Oct 20]. Available from: https://www.cdc.gov/ncbddd/autism/facts.html.

3. World Health Organization (2014). Comprehensive and coordinated efforts for the management of Autism spectrum disorders, World Health Organization.

4. Nguyễn Thị Hương Giang và cộng sự (2010), "Nghiên cứu một số nguy cơ của trẻ tự kỷ từ 18 tháng đến 36 tháng tuổi", Tạp chí y học thực hành, 739(10/2010), Tr.16-18.

5. Phuong Minh Nguyen, Thien Thang Tran (2021), "Clinical characteristics and associated socio-demographic factors of autism spectrum disorder in Vietnamese children", Curr Pediatr Res2021; 25 (1): 308-312

6. Trân Thiện Thẳng (2019), "Khảo sát tỷ lệ trẻ từ 18-36 tháng có biểu hiện rối loạn phổ tự kỷ tại phòng khám bệnh viện nhi đồng cân thơ bằng thang điểm M-CंHAT", Tạp Chí Y Dược Học Cần Tho, 22-25,tr. 293-304.

7. Nguyễn Đức Trí, Trân Diệp Tuấn, (2014), "Nghiên cứu tỷ lê M-CHAT dưởng tính (nguy cơ bi rối loạn phổ tự kỷ): Một khảo sát tại cộng đông trẻ hoc mầm non từ 16-36 tháng trong Quận Ninh Kiêu, thành phố Cần Thơ", Tạp chí nghiên cứu y học TP. Hồ Chí Minh, 18, tr.454-458.

\section{BÊNNH QUANH RĂNG VÀ MộT SỐ YẾU TỐ LIÊN QUAN Ở TRẺ MẮC HộI CHỨNG THÂ̂N HƯ TIÊN PHÁT}

\section{Lương Minh Hằng ${ }^{1}$, Tống Minh Sơn ${ }^{1}$, Trần Huy Thịnh², Trần Thị Mỹ Hạnh ${ }^{1}$, Đào Thị Hằng $\mathrm{Nga}^{1}$}

\section{TÓM TẮT}

Hôi chứng thân hư (HCTH) là bênh lý câu thận hay gặp nhất ở trẻ em với tỉ lệ mới mắc hàng năm là 2 7/100000 trẻ trên tổng tỉ lệ mắc bênh là $16 / 100000$ trẻ. Tại Việt Nam (1981-1990) có 1414 trẻ mắc HCTH nhập Bênh viên Nhi Trung ương, chiếm $46,6 \%$ tổng số bệnh nhân cửa Khoa Thận - Tiết niệu, trong đó 1358 trẻ được chẩn đoán HCTHH tiên phát $(91,0 \%)$. Theo y văn, những trẻ mắc HCTH có sự tác động phá hủy mô

1 Viện Đào tạo Răng Hàm Mặt-Trường Đại học Y Hà Nội 2Trường Đại hoc Y Hà Nôi

Chịu trách nhiệm chính: Lương Minh Hằng

Email: minhhang@hmu.edu.vn

Ngày nhận bài: 3.3.2021

Ngày phản biên khoa hoc: 22.4.2021

Ngày duyệt băi: 29.4.2021 quanh răng khi sử dụng kéo dài các loại thuốc trong điều trị bệnh. Ngoài ra, sự nhập viện thường xuyên và chế độ ăn uống riêng biệt cững ảnh hưởng đến việc chăm sóc vệ sinh răng miệng làm tăng tỉ lệ bệnh quanh răng ở trẻ. Nghiên cứu này nhằm mục đích mô tả thực trang bênh quanh răng và mối liên quan giữa bệnh và HCTH tiên phát ở trẻ em tại bệnh viện Nhi Trung ương. Phương pháp nghiên cứu mô tả cắt ngang được thực hiện ở 407 trẻ). Kết quả nghiên cứu cho thấy đa sổ trẻ viêm lơi và phì đai lợi đô 1 , cao răng gặp nhiều nhất ở trẻ 13-18 tuổi, có mối liên quan giữa thời gian mắc bênh, số lần tái phát, thể bệnh, việc sử dụng loại thuốc điêu trị và bệnh viêm lợi, phì đại lợi ở nhóm đối tướng nghiên cứu.

Tư khóa: hội chứng thận hư tiên phát, bệnh quanh răng, viêm lị̂i, lợi phì đại, cao răng, mối liên quan.

\section{SUMMARY}

